\title{
Alcohol misuse among women in Brazil: recent trends and associations with unprotected sex, early pregnancy, and abortion
}

\author{
Luciana T.S. Massaro, ${ }^{1,2}$ iD Renata R. Abdalla, ${ }^{1,2}$ iD Ronaldo Laranjeira, ${ }^{1,2}$ iD Raul Caetano, ${ }^{3}$ (iD Ilana \\ Pinsky, ${ }^{1}$ Clarice S. Madruga ${ }^{1,2}$ iD \\ ${ }^{1}$ Instituto Nacional de Ciência e Tecnologia para Políticas Públicas do Álcool e Outras Drogas (INPAD), Departamento de Psiquiatria e \\ Psicologia Médica, Universidade Federal de São Paulo (UNIFESP), São Paulo, SP, Brazil. ${ }^{2}$ Departamento de Psiquiatria e Psicologia Médica, \\ UNIFESP, São Paulo, SP, Brazil. ${ }^{3}$ Prevention Research Center, Oakland, CA, USA. ID LTSM https://orcid.org/0000-0003-2877-2195, \\ iD RRA https://orcid.org/0000-0001-9936-8937, iD RL https://orcid.org/0000-0003-3009-1778, iD RC https://orcid.org/0000-0002-5036- \\ 5249, iD CSM https://orcid.org/0000-0003-1993-1748
}

\begin{abstract}
Objective: This study compared the rates of binge drinking (BD) and alcohol use disorder (AUD) reported for 2006 with those reported for 2012, exploring their associations with unprotected sex, early pregnancy, and abortion in a representative sample of women in Brazilian households.

Methods: This was a descriptive analysis of data from a cross-sectional study involving randomized multistage cluster sampling of the population $\geqslant 14$ years of age. Weighted prevalence rates and odds ratios were estimated, and serial mediation analysis was performed.

Results: A total of 4,256 women were analyzed. The BD prevalence was $35.1 \%$ and $47.1 \%$ in 2006 and 2012, respectively, a significant increase, especially among women 40-59 years of age. There was no significant difference in AUD prevalence. BD (without AUD) was found to increase the odds of unprotected sex and abortion. The path analysis showed that early pregnancy was a mediator of the relationship between alcohol consumption and abortion.

Conclusion: Among women in Brazil, the harmful use of alcohol is increasing, which has an impact on female reproductive health and exposure to risks. There is a need for specific prevention initiatives focusing on alcohol-related behaviors in women.
\end{abstract}

Keywords: Brazil; alcohol abuse; binge drinking; female; abortion

\section{Introduction}

Among women, alcohol consumption is responsible for $2.3 \%$ of the global burden of disease and injury, and $4 \%$ of all deaths among women were attributed to alcohol use in 2012. ${ }^{1}$ In low- and middle-income countries (LMICs), where drastic changes in gender-specific social roles and the economic status of women have narrowed the cultural gaps between men and women, increased alcohol consumption due to harmful drinking patterns is being reported among women. ${ }^{2,3}$

Clinical studies have shown that once substance use has been initiated, the rates of alcohol, cannabis, opioid, and cocaine consumption tend to increase more rapidly in women than in men, and that women may progress to drug use disorders and dependence more quickly than men. ${ }^{4}$ There is also a large body of evidence suggesting an association between alcohol misuse and a variety of risk behaviors, which can have a particularly negative impact on the biopsychosocial well-being of women. ${ }^{5,6}$ Examples of negative outcomes commonly associated with the misuse of alcohol by women include unprotected sex, early unplanned

Correspondence: Clarice S. Madruga, Departamento de Psiquiatria e Psicologia Médica, Universidade Federal de São Paulo, Rua Borges Lagoa, 570, sala 82, CEP 04038-000, São Paulo, SP, Brazil.

E-mail: clarice@ uniad.org.br

Submitted Aug 06 2017, accepted May 08 2018, Epub Oct 222018. pregnancies, and abortions..$^{7-9}$ Such risk behaviors are already quite prevalent among Brazilian women, ${ }^{10}$ and can be considered public health issues regardless of the chance of being magnified by alcohol misuse.

The aim of this study was to respond to an urgent demand for up-to-date information regarding trends in alcohol consumption among women in Brazil, as well as to investigate the rates of unprotected sex, early pregnancy, and abortion, evaluating their associations with alcohol consumption. We also examined the effect of alcohol misuse on abortion, analyzing the potential mediating roles of unprotected sex and early pregnancy. A deeper understanding of such associations will be of great value for developing tailored prevention strategies and providing individualized health care.

\section{Methods}

This was a descriptive, cross-sectional analytical study. Data were obtained from the Brazilian National Alcohol and Drug Survey, commonly known in Brazil by the acronym
How to cite this article: Massaro LTS, Abdalla RR, Laranjeira R, Caetano R, Pinsky I, Madruga CS. Alcohol misuse among women in Brazil: recent trends and associations with unprotected sex, early pregnancy, and abortion. Braz J Psychiatry. 2019;41:131-137. http:// dx.doi.org/10.1590/1516-4446-2017-0024 
LENAD (Levantamento Nacional de Álcool e Drogas), a serial cross-sectional study conducted in 2006 and 2012.

\section{Sampling and procedures}

The LENAD, which was conducted by the research firm Ipsos Public Affairs, used randomized multistage cluster sampling to select 3,007 and 4,607 individuals, respectively, in 2006 and 2012. This technique was used to guarantee that the sample represents specific sub-groups or strata with higher statistical precision, since variability within each subgroup is lower than variability in the entire population. As this technique has high statistical precision, it also allows for smaller sample sizes than would be otherwise required.

The sample consisted of individuals $\geqslant 14$ years of age, including an oversampling of adolescents (14-17 years of age), who were selected from the household population of Brazil. Residents of Brazil who do not speak Portuguese (e.g., native Brazilians living in the Amazon rainforest) were excluded, as were individuals with cognitive impairment or intellectual disability. The overall response rates in 2006 and 2012 were 66 and $77 \%$, respectively. The sampling process was conducted in three steps: 1) the selection of 143 counties in 2006 and 149 counties in 2012 using probability-proportional-to-size methods; 2) the selection, using those same methods, of two census sectors within each county, totaling 298 census sectors; and 3 ) the selection, by simple random sampling, of eight households within each census sector, followed by the selection of one household member to be interviewed with the nearest-birthday method. One-hour, face-to-face interviews were conducted in the home of the respondent by trained interviewers who used a standardized, fully structured questionnaire. In the present study, we analyzed the female subsample, which included 1,719 respondents in 2006 and 2,537 in 2012, for a collective total of 4,256 women.

\section{Ethics}

This study was approved by the research ethics committee of the Universidade Federal de São Paulo (UNIFESP), São Paulo, Brazil. All respondents gave written informed consent.

\section{Socioeconomic and demographic characteristics}

The variables of interest were evaluated in relation to the main socioeconomic and demographic characteristics (sex, age, level of education, marital status, and socioeconomic status). We also evaluated those variables according to the principal geographic regions of Brazil: the north, northeast, midwest, southeast and south.

\section{Associated variables}

Alcohol use disorder (AUD)

AUD was assessed with the Portuguese-language version of the Composite International Diagnostic Interview
(CIDI 2.1) adapted for use in Brazil. ${ }^{11}$ Although both the 2006 and 2012 LENAD series pre-dated the fifth edition of the DSM-5, the questionnaire included questions related to craving, which allowed AUD to be diagnosed on the basis of the 11 corresponding DSM- 5 criteria. Individuals who met two or more of those criteria in the past 12 months were classified as having AUD.

\section{Binge drinking (BD)}

We defined $\mathrm{BD}$ as the National Advisory Council proposed to the National Institute on Alcohol Abuse and Alcoholism in 2004: a pattern of drinking that brings the blood alcohol concentration to $0.08 \mathrm{~g} / \mathrm{dL}$ or higher. For the typical adult, this pattern corresponds to women consuming $\geqslant 4$ drinks over a period of approximately 2 hours. ${ }^{12}$ The questionnaire addressed this subject with the following yes-no question: On any given occasion in the last 12 months, have you drunk four or more servings of any alcoholic beverage over a period of approximately 2 hours?

In the statistical models, we tested the alcohol use status (AUS) variable. The AUS score combines AUD and $\mathrm{BD}$ as follows: $0=$ moderate drinker (no BD or AUD), $1=$ binge drinker (BD without $A U D)$, and $2=$ problem drinker $(B D+A U D)$.

\section{Abortion}

The history of abortion was assessed by a yes/no question: Have you ever aborted a pregnancy?

\section{Unprotected sex}

The frequency of unprotected sex was assessed by the question: How often do you use a condom when you have sex? The responses included never, almost never, almost always, and always, coded $0,1,2$, and 3 , respectively.

\section{Early pregnancy}

Early pregnancy was defined as that occurring in females under 20 years of age..$^{13}$ It was assessed by the following yes/no question: Have you ever been pregnant?

\section{Statistical analysis}

All preliminary findings were analyzed using Stata version 13.0. ${ }^{14}$ Prevalence rates were estimated using weighted data to correct for unequal probabilities of sample selection. Post-stratification weights were applied to correct for non-responses and to adjust the 2006 and 2012 samples to known population distributions of selected socioeconomic and demographic variables (age, level of education, marital status, socioeconomic status, and region of the country) according to the Brazilian Census of 2010. ${ }^{15}$ Cross-tabulations were used to examine alcohol consumption by socioeconomic and demographic characteristics.

We used multinomial regression to assess the unconditional associations between AUS (moderate drinker, binge drinker, or problem drinker) and three possible outcomes (unprotected sex, early pregnancy, and abortion). 


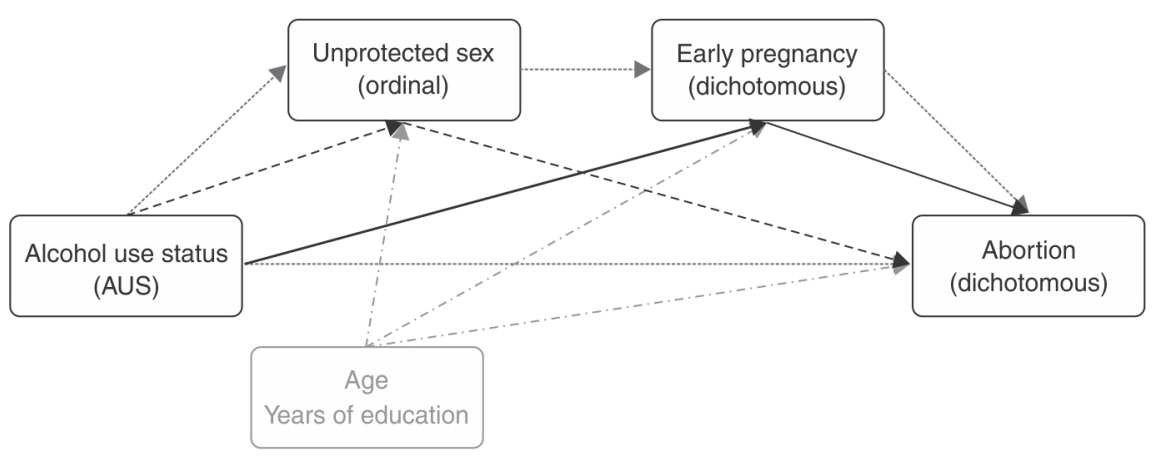

— Path statistically significant - (AUS > Early pregnancy $>$ Abortion)

Figure 1 Serial mediation model: the higher the AUS value, the higher the probability of abortion through early pregnancy, independent of the frequency of protected sex. AUS = alcohol use status.

All multinomial models were adjusted for age and education level.

\section{Serial mediation analysis}

Serial mediation analysis was performed using Mplus version 7.4 (Muthén \& Muthén, 1998-2015) as depicted in Figure 1. Two potential mediators were analyzed unprotected sex (as an ordinal variable) and early pregnancy (as a dichotomous variable: $0=$ no early pregnancy and $1=$ early pregnancy). Abortion was also analyzed as a dichotomous variable. The control variables were age and years of education, which were regressed on unprotected sex, early pregnancy, and abortion.

The parameterization and the weighted least squares mean- and variance-adjusted (WLSMV) estimator, employing a diagonal weight matrix with standard errors, were employed as suggested by Muthén et al. ${ }^{16}$ In WLSMV estimation, the indirect effect is determined by analyzing the latent response variables underlying the categorical variables (the two mediators), rather than the categorical variables themselves. ${ }^{17}$ In addition, the indirect effects were calculated based on bootstrap resampling (with 10,000 replicates). Thus, $95 \%$ bootstrap confidence intervals $(\mathrm{Cls})$ are estimated, and when those Cls encompass 0 , the null hypothesis (of no indirect effect) is accepted. Due to the theta parameterization, estimations of the indirect effects are given in probit regression. Because no effect size is estimated for the indirect effect, the results are interpreted only in terms of their significance and direction regarding increasing or decreasing probabilities. Positive values indicate an increase in the probability of abortion, whereas negative values indicate a reduction in that probability.

\section{Results}

\section{Binge drinking}

The prevalence of $\mathrm{BD}$ among women increased by $34.2 \%$ (i.e., from 35.1 to $47.1 \%$ ) between 2006 and 2012 (Table 1). With the exception of the north, BD increased in all regions of the country. The increase was largest
$(68.4 \%)$ in the midwest and smallest (10.2\%) in the south. Among women $40-59$ years of age, the prevalence of BD increased by $88.4 \%$ (from 26.8 to $50.5 \%$ ), and there was also a significantly greater increase in that prevalence among women with a lower education level $(70.7 \%$ among those with $\leqslant 9$ years of education vs. $24.5 \%$ among those with $\leqslant 12$ years of education).

\section{Alcohol use disorder}

In the sample of women as a whole, the prevalence of AUD did not change significantly between 2006 (5.9\%) and $2012(6.1 \%)$ (Table 1). As for regional differences, the only significant reduction in AUD prevalence was in the south (from 7.6 to $5.2 \%$ ). However, there were significant reductions in that prevalence in two age groups: women 14-17 years of age, among whom it decreased by $33.3 \%$ (from 6 to $4 \%$ ), and women $18-28$ years of age, among whom it decreased by $15.5 \%$ (from 10.3 to $8.7 \%$ ).

\section{Risk behaviors}

Table 2 shows the prevalence rates and associations for the 2012 dataset only, since LENAD II involved methodological improvements to avoid underreporting in the assessment of risk behaviors. That change confounds comparisons between the two waves (2006 and 2012) regarding risk behaviors rates. Unprotected sex was reported by $36.1 \%$ of the women in the sample, and $11.3 \%$ of the women $\leqslant 20$ years of age reported having been pregnant at least once. Abortion was reported by $16.3 \%$ of those women. When estimated for the three AUS categories - moderate drinker, binge drinker, and problem drinker - those rates increased in a doseresponse pattern. Approximately half of the women who reported $\mathrm{BD}$ also reported having had unprotected sex, with $\mathrm{BD}$ increasing the chances of engaging in unprotected sex by 1.5 times. Among women $\leqslant 20$ years of age who reported $\mathrm{BD}$, more than one in 10 had been or were currently pregnant, and the chances of having an abortion were almost double that calculated for those who did not report BD. Among the women classified as problem drinkers, the abortion rate was nearly $25 \%$. 
Table 1 Prevalence of binge drinking and alcohol use disorder among women $(n=4,256)$ in 2006 and 2012 , by socioeconomic and demographic characteristics

\begin{tabular}{|c|c|c|c|c|c|c|}
\hline \multirow[b]{2}{*}{ Characteristic } & \multicolumn{3}{|c|}{ Binge drinking* } & \multicolumn{3}{|c|}{ Alcohol use disorder ${ }^{\dagger}$} \\
\hline & 2006 & 2012 & $\begin{array}{c}\text { Relative } \\
\text { difference (\%) }\end{array}$ & 2006 & 2012 & $\begin{array}{c}\text { Relative } \\
\text { difference (\%) }\end{array}$ \\
\hline Sample as a whole & $35.1(30.2-40.2)$ & $47.1(42.4-51.8)$ & $34.2^{*}$ & $5.9(4.6-7.5)$ & $6.1(4.8-7.7)$ & 3.39 \\
\hline $\begin{array}{l}\text { Age, years } \\
14-17 \\
18-28 \\
29-39 \\
40-59 \\
\geqslant 60\end{array}$ & $\begin{array}{c}30.9(21.8-41.8) \\
42.8(35.2-50.8) \\
38.0(29.9-46.8) \\
26.8(19.9-35.1) \\
20.8(9.7-39.0)\end{array}$ & $\begin{array}{c}39.5(28.9-51.2) \\
46.0(38.4-53.7) \\
52.3(44.7-59.7) \\
50.5(42.3-58.6) \\
22.2(9.6-43.2)\end{array}$ & $\begin{array}{c}27.8 \\
7.5 \\
37.6 \\
88.4 \\
6.7\end{array}$ & $\begin{array}{c}6.0(3.5-10.2) \\
10.3(7.2-14.5) \\
6.8(4.0-11.5) \\
4.0(2.6-6.1) \\
0.3(0.0-2.1)\end{array}$ & $\begin{array}{l}4.0(2.4-6.7) \\
8.7(5.8-13.0) \\
8.3(5.8-11.7) \\
5.8(3.8-8.8) \\
0.5(0.1-1.8)\end{array}$ & $\begin{array}{c}-33.3^{\ddagger} \\
-15.5^{\ddagger} \\
22.1 \\
45.0 \\
67.0\end{array}$ \\
\hline $\begin{array}{l}\text { Education } \\
\qquad \begin{array}{l}\geqslant 9 \\
\geqslant 12 \\
>12\end{array}\end{array}$ & $\begin{array}{l}33.4(26.5-41.0) \\
38.7(32.7-45.1) \\
23.7(13.4-38.3)\end{array}$ & $\begin{array}{l}57.0(49.5-64.2) \\
48.2(42.1-54.3) \\
32.4(24.1-42.1)\end{array}$ & $\begin{array}{l}70.7^{\ddagger} \\
24.5^{\ddagger} \\
36.7\end{array}$ & $\begin{array}{c}5.1(3.5-7.3) \\
6.9(5.1-9.4) \\
4.6(1.9-10.4)\end{array}$ & $\begin{array}{l}6.1(4.2-8.8) \\
6.4(4.7-8.7) \\
5.0(2.6-9.6)\end{array}$ & $\begin{array}{l}19.6 \\
-7.2 \\
8.7\end{array}$ \\
\hline $\begin{array}{l}\text { Marital status } \\
\text { Single } \\
\text { Married } \\
\text { Widowed } \\
\text { Divorced/separated }\end{array}$ & $\begin{array}{l}43.8(36.1-51.7) \\
29.7(23.7-36.5) \\
32.0(16.6-52.7) \\
32.3(20.3-47.1)\end{array}$ & $\begin{array}{l}48.6(40.5-56.7) \\
44.4(38.9-50.0) \\
57.6(38.8-74.4) \\
60.1(45.5-73.0)\end{array}$ & $\begin{array}{l}11.0 \\
49.5 \\
80.0 \\
86.0\end{array}$ & $\begin{array}{c}8.9(6.3-12.6) \\
4.3(2.9-6.3) \\
5.2(2.5-10.6\} \\
5.5(2.8-10.4)\end{array}$ & $\begin{array}{l}6.6(4.4-9.8) \\
5.8(4.1-8.1) \\
3.2(1.1-8.9) \\
9.8(5.8-16.3)\end{array}$ & $\begin{array}{l}-25.8 \\
34.9 \\
-38.5 \\
78.2\end{array}$ \\
\hline $\begin{array}{l}\text { Socioeconomic class } \\
\text { A } \\
\text { B } \\
\text { C } \\
\text { D } \\
\text { E }\end{array}$ & $\begin{array}{l}27.7(10.7-55.1) \\
31.6(22.2-42.8) \\
35.1(28.0-42.9) \\
35.7(28.4-43.8) \\
47.5(24.4-71.7)\end{array}$ & $\begin{array}{l}23.7(10.4-45.4) \\
40.6(32.8-48.3) \\
51.5(45.1-57.9) \\
52.5(42.0-62.8) \\
57.7(42.1-72.0)\end{array}$ & $\begin{array}{l}-14.4 \\
28.5 \\
46.7 \\
47.1 \\
21.5\end{array}$ & $\begin{array}{c}7.3(2.1-22.4) \\
5.7(3.0-10.5) \\
7.7(5.5-10.8) \\
4.4(2.9-6.7) \\
6.7(2.8-15.2)\end{array}$ & $\begin{array}{l}4.0(0.9-16.7) \\
5.3(3.4-8.3) \\
7.2(5.2-9.8) \\
4.6(2.6-8.0) \\
6.0(4.7-7.6)\end{array}$ & $\begin{array}{l}-45.2 \\
-7.0 \\
-6.5 \\
4.5 \\
-10\end{array}$ \\
\hline $\begin{array}{l}\text { Region } \\
\text { Northern } \\
\text { Northeastern } \\
\text { Southeastern } \\
\text { Southern } \\
\text { Central-west }\end{array}$ & $\begin{array}{l}39.2(24.1-56.6) \\
37.2(27.6-47.9) \\
33.1(26.1-41.0) \\
39.1(28.0-51.4) \\
24.4(14.9-37.3)\end{array}$ & $\begin{array}{l}42.3(27.5-58.6) \\
62.1(53.9-69.7) \\
42.3(35.3-49.7) \\
43.1(30.7-56.6) \\
41.1(28.3-55.2)\end{array}$ & $\begin{array}{l}7.9 \\
66.9^{\ddagger} \\
27.8^{\ddagger} \\
10.2^{\ddagger} \\
68.4^{\ddagger}\end{array}$ & $\begin{array}{l}5.7(2.3-13.4) \\
3.5(1.9-6.4) \\
6.4(4.5-9.0) \\
7.6(4.1-13.4) \\
9.0(4.4-17.4)\end{array}$ & $\begin{array}{c}10.0(6.0-16.4) \\
3.5(1.8-6.9) \\
6.7(4.6-9.6) \\
5.2(3.1-8.8) \\
9.5(5.2-16.8)\end{array}$ & $\begin{array}{c}75.4 \\
0 \\
4.7 \\
-31.6^{\ddagger} \\
5.6\end{array}$ \\
\hline Depressive disorder & $38.6(31.4-46.4)$ & $52.8(43.9-61.5)$ & 36.8 & $9.3(6.8-12.4)$ & $9.3(6.7-12.8)$ & 0 \\
\hline
\end{tabular}

Data presented as \% (95\% confidence interval).

* Defined as the ingestion of four units of alcohol within 2 hours (calculated among drinkers).

As defined in the DSM-5.

$\$ p<0.05$ for the comparison between 2006 and 2012 (chi-square test).

$\S$ Categories established by the Brazilian Marketing Research Association, class A being the most affluent.

Table 2 Logistic regression, adjusted for age and education, of prevalence rates and odds ratios for unprotected sex, early pregnancy, and abortion among women according to alcohol use status in 2012

\begin{tabular}{lcccc}
\hline Variable & Sample as a whole $(\mathrm{n}=2,537)$ & No BD, no AUD & BD, no AUD & BD + AUD \\
\hline $\begin{array}{l}\text { Unprotected sex } \\
\%(95 \% \mathrm{Cl})\end{array}$ & $36.1(33.2-39.1)$ & $32.7(29.4-36.1)$ & $48.5(39.9-57.2)$ & $1.5(1.0-2.2)^{*}$ \\
OR $(95 \% \mathrm{Cl})$ & - & 1 & & \\
Early pregnancy & & & & \\
$\%(95 \% \mathrm{Cl})$ & $11.3(8.8-14.5)$ & $10.4(8.0-13.6)$ & $10.6(4.4-23.5)$ & $25.8(15.1-40.6 .6)$ \\
OR $(95 \% \mathrm{Cl})$ & - & 1 & $1.2(0.4-3.3)$ & $3.1(1.5-6.4)^{*}$ \\
Abortion & & & & \\
$\%(95 \% \mathrm{Cl})$ & $16.3(14.5-18.3)$ & $15(13.2-17.0)$ & $20.4(15.3-26.7)$ & $24.9(16.3-36.2)$ \\
OR $(95 \% \mathrm{Cl})$ & - & 1 & $1.9(1.3-2.8)^{\dagger}$ & $2.5(1.5-4.4)^{\dagger}$ \\
\hline
\end{tabular}

$95 \% \mathrm{Cl}=95 \%$ confidence interval; $\mathrm{AUD}=$ alcohol use disorder; $\mathrm{BD}=$ binge drinking; $\mathrm{OR}=$ odds ratio.

$* p<0.05 ;{ }^{\dagger} p<0.01$.

Those same women were also 3.0 times more likely to have had an early pregnancy and 2.5 times more likely to have had an abortion than those classified as moderate drinkers.

\section{Path analysis}

As indicated in Figure 1, regarding the indirect specific effects, only one specific path was statistically significant 
(AUS $\rightarrow$ early pregnancy $\rightarrow$ abortion [indirect effect $=$ $0.267,95 \%$ bootstrap $\mathrm{Cl}=0.051-0.483]$ ), indicating that higher scores for alcohol dependence or BD (i.e., higher AUS scores) translate to a higher probability of abortion, the conditional path passing through early pregnancy, independent of the frequency of unprotected sex. There was no evidence that the following specific indirect effects (paths) were significant: AUS $\rightarrow$ unprotected sex $\rightarrow$ abortion (indirect effect $=-0.002,95 \%$ bootstrap $\mathrm{Cl}=$ -0.034 to 0.031 ), and AUS $\rightarrow$ unprotected sex $\rightarrow$ early pregnancy $\rightarrow$ abortion (indirect effect $=0.011$, 95\% bootstrap $\mathrm{Cl}=-0.015$ to 0.037 ). In addition, when early pregnancy was excluded from the analysis, there was no evidence that AUS had a direct effect on abortion probability (direct effect $=0.142,95 \% \mathrm{Cl}=-0.103$ to 0.386 ).

\section{Discussion}

Our findings show there was an increase in BD between 2006 and 2012 among women in Brazil. This increase was significant in some subpopulations, such as poorly educated women between 40 and 59 years of age of low socioeconomic status. Increased drinking and alcoholrelated problems among women have been reported in various studies and have been brought to public attention by several organizations. ${ }^{1}$ In Brazil, there is a lack of focused, effective public health policies to limit the activities of the alcohol industry, as is common in LMICs, ${ }^{18}$ which is partially responsible for this situation. The impact of that shortcoming is augmented by the scarcity of womencentered health care services, ${ }^{19,20}$ which is attributable to the combination of a disorganized health care network and the use of treatment protocols that focus on men. ${ }^{3,5}$

We did not detect any significant changes in AUD during the study period, although the rates significantly decreased among specific subpopulations, such as younger women and women living in the southern region of the country. Although the BD rate increased between 2006 and 2012, that increase was more moderate in the south. It should be borne in mind that previous studies have shown the rates of alcohol consumption among adolescents to be highest in the south, ${ }^{21,22}$ which led to several regional environmental prevention initiatives. ${ }^{23,24}$ Our findings suggest that such strategies might have succeeded in changing harmful drinking behaviors in that population. $^{25}$ The fact that prevention programs were concentrated in school settings, ${ }^{26}$ combined with the lack of universal and selected prevention initiatives for the population as a whole, could explain the significant decrease among women 14-28 years of age, whereas there was a $45 \%$ increase among women $40-59$ years of age. However, such speculation contradicts evidence that school prevention initiatives are ineffective in contexts with a lack of environmental prevention. ${ }^{27}$

The current rates of AUD in Brazil are still a matter of concern, since it affects more than $6 \%$ of the female population. This rate is well above the $3.2 \%$ observed among women in the Americas and higher than the $2.9 \%$ observed among women in Europe. ${ }^{1}$ The stable but consistently elevated rates of AUD among females in
Brazil should be the focus of more detailed investigation in the future.

There is a large body of evidence suggesting that abusive alcohol consumption is closely related to a range of risk behaviors and negative events, especially in LMICs such as Brazil. ${ }^{28} \mathrm{~A}$ previous study on sexual practices in a population sample from a southeastern Brazilian capital found that 14 and $23 \%$ of drug-using adolescents reported unprotected sex and abortion, respectively, with nearly one third of them reporting early pregnancy. ${ }^{29}$ Our findings show that the rates of unprotected sex, early pregnancy, and abortion are worryingly high in Brazil, and that those events are significantly associated with AUD. The results suggested a dose-response relationship between AUS and the investigated outcomes, in which either AUD or BD alone were sufficient to predict unprotected sex and abortion.

Our results show that more than one in 10 women in Brazil $\leqslant 20$ years of age have been pregnant. Teenage pregnancy is a serious public health issue in LMICs, including Brazil, due to the short- and long-term negative consequences for mother and child. ${ }^{30}$ Our findings also show that more than $16 \%$ of the female population $\geqslant 14$ years of age reported having had at least one pregnancy terminated, a rate well above the $9 \%$ previously estimated. ${ }^{10}$ Abortion is currently prohibited in Brazil (except in cases in which the life of the mother is at immediate risk, rape, and anencephaly). ${ }^{31}$ That discrepancy may be attributed to the discretionary method employed in drug use surveys such as this one. In addition to increasing public health care costs in the country, ${ }^{32}$ unsafe abortion is one of the main causes of maternal mortality, death resulting from physical complications and psychosocial factors. ${ }^{33}$ Although some interventions can be safe, simple, and effective, it is estimated that nearly 22 million unsafe abortions take place every year worldwide, significantly contributing to the global burden of maternal mortality and morbidity. ${ }^{34}$ In a recent survey, it was estimated that nearly 17 million unsafe abortions were performed in Brazil between 1996 and 2012, with an average of approximately 1 million procedures per year. ${ }^{35}$ Brazil's current restricted abortion legislation leads women faced with unwanted pregnancies to practice self-induced abortion or undergo the procedure at clandestine abortion clinics, putting their lives at risk. Policy and regulatory barriers also limit access to post-abortion services, resulting in missed opportunities for educational and therapeutic interventions that could prevent future abortions. ${ }^{34}$

The serial mediation model confirmed that harmful AUS (BD or BD + AUD) increases the probability of abortion via early pregnancy, although that relationship was not found to be dependent on the frequency of unprotected sex. To our knowledge, the proposed path from AUS to abortion has not previously been explored. However, our hypothesis is in line with previous evidence showing an association between AUS and early pregnancy, ${ }^{36-38}$ as well as between AUS and abortion. 9,39 The association between harmful drinking patterns and unprotected sex has been quite well established in the literature. ${ }^{38,40}$ Contrary to our hypothesis, we did not find unprotected sex to be a mediator of the association between AUS and abortion. 
We can speculate that even though the rates of unprotected sex were high (being reported by more than one third of the female population), it does not necessarily lead to pregnancy, a necessary condition for the abortion outcome. Therefore, unprotected sex was not found to play a role in that relationship. Due to the cross-sectional design of the study, a causal chain cannot be established, since it is not possible to known if women abort because they drink more and, therefore, expose themselves to unprotected sex, or if they drink more after the traumatic experience of abortion or if they had a previous pattern of carelessness regarding sexual exposure. Although we cannot make inferences regarding causal influences, the associations presented here are strong enough to indicate the need for the development of future longitudinal studies on alcohol use to explore causal mechanisms related to the impacts of alcohol use on risk exposure and female reproductive health.

The intrinsic limitations of this study should be mentioned. Due to methodological changes in data collection between 2006 and 2012, it was not possible to analyze the trends of risk behaviors between the two waves of the survey.

Furthermore, the use of a cross-sectional design demands very careful interpretation of path analysis models, which should avoid, by all means, any assumption regarding causal relationships between the studied variables.

Finally, this study provides sufficient evidence of a recent increase in the harmful consumption of alcohol among women in Brazil. Our results also call attention to a series of risk behaviors associated with alcohol misuse, and we have proposed a model to explain those associations: the predictor alcohol misuse has a direct effect on abortion, which is mediated by early pregnancy. Because the harmful use of alcohol is avoidable, it is of utmost importance that universal and selective prevention initiatives focusing on alcohol-related behaviors be implemented among women in Brazil.

\section{Acknowledgements}

This study was supported by grants from the Conselho Nacional de Desenvolvimento Científico e Tecnológico (CNPq) during the design and conduct of the survey and from the Coordenação de Aperfeiçoamento de Pessoal de Nível Superior (CAPES; finance code 001) during the data analysis and interpretation stages.

\section{Disclosure}

The authors report no conflicts of interest.

\section{References}

1 World Health Organization (WHO). Global status report on alcohol and health - 2014 [Internet]. 2014 [cited 2018 May 21]. http://www. who.int/substance_abuse/publications/global_alcohol_report/en/

2 Colell E, Sanchez-Niubo A, Domingo-Salvany A. Sex differences in the cumulative incidence of substance use by birth cohort. Int J Drug Policy. 2013;24:319-25.

3 Kim W, Kim S. Women's alcohol use and alcoholism in Korea. Subst Use Misuse. 2008;43:1078-87.
4 Becker JB, Hu M. Sex differences in drug abuse. Front Neuroendocrinol. 2008;29:36-47.

5 Pillon SC, dos Santos MA, Florido LM, et al. Consequências do uso de álcool em mulheres atendidas em um centro de atenção psicossocial [Internet]. 2014 [cited 2018 May 21]. https://www.researchgate.net/ publication/264637336_Consequencias_do_uso_de_alcool_em_ mulheres_atendidas_em_um_Centro_de_Atencao_Psicossocial.

6 Jessor R. Risk behavior in adolescence: a psychosocial framework for understanding and action. J Adolesc Health. 1991;12:597-605.

7 Mastroleo NR, Operario D, Barnett NP, Colby SM, Kahler CW, Monti PM. Prevalence of heavy drinking and risky sexual behaviors in adult emergency department patients. Alcohol Clin Exp Res. 2015;39: 1997-2002.

8 Iversen ML, Sorensen NO, Broberg L, Damm P, Hedegaard M, Tabor $A$, et al. Alcohol consumption and binge drinking in early pregnancy. A cross-sectional study with data from the Copenhagen pregnancy cohort. BMC Pregnancy Childbirth. 2015;15:327.

9 Keenan K, Grundy E, Kenward MG, et al. Women's risk of repeat abortions is strongly associated with alcohol consumption: a longitudinal analysis of a Russia national pane study 1994-2009. PLoS One. 2014;9:e90356.

10 Diniz D, Corrêa M, Squinca F, Braga KS. [Abortion: 20 years of Brazilian research]. Cad Saude Publica. 2009;25:939-42.

11 Quintana MI, Andreoli SB, Jorge MR, Gastal FL, Miranda CT. The reliability of the Brazilian version of the Composite International Diagnostic Interview (CIDI 2.1). Braz J Med Biol Res. 2004;37: 1739-45.

12 NIAAA. Definition of binge drinking [Internet]. 2004 [cited 2018 May 21]. pubs.niaaa.nih.gov/publications/Newsletter/winter2004/Newsletter_ Number3.pdf

13 Chelala CA. La salud de los adolescentes y los jóvenes en las Américas: escrebiendo el futuro. Washington: Organización Panamericana de la Salud; 1995.

14 StataCorp. 2013. Stata Statistical Software: Release 13. College Station: StataCorp LP; 2013.

15 Instituto Brasileiro de Geografia e Estatística (IBGE). Censo demográfico 2010: resultados gerais da amostra [Internet]. 2010 [cited 2018 May 21]. https://ww2.ibge.gov.br/home/estatistica/populacao/ censo2010/resultados_gerais_amostra/default_resultados_gerais_ amostra.shtm

16 Muthén BO, du Toit SHC, Spisic D. Robust inference using weighted least squares and quadratic estimating equations in latent variable modeling with categorical and continuous outcomes. Psychometrika. 1997;49:115-32.

17 Muthén BO, Muthén LK, Asparouhov T. Regression and mediation analysis using Mplus. Los Angeles: Muthén \& Muthén; 2016.

18 Caetano R, Mills B, Madruga C, Pinsky I, Laranjeira R. Discrepant trends in income, drinking, and alcohol problems in an emergent economy: Brazil 2006 to 2012. Alcohol Clin Exp Res. 2015;39:863-71.

19 Elbreder MF, Laranjeira R, Siqueira MMd, Barbosa DA. Perfil de mulheres usuárias de álcool em ambulatório especializado em dependência química. J Bras Psiquiatr. 2008;57:9-15.

20 Otiashvili D, Kirtadze I, O'Grady KE, Zule W, Krupitsky E, Wechsberg $W M$, et al. Access to treatment for substance-using women in the Republic of Georgia: socio-cultural and structural barriers. Int J Drug Policy. 2013;24:566-72.

21 Galduróz JCF, Noto AR, Fonseca AM, Carlini EA. V Levantamento nacional sobre o consumo de drogas psicotrópicas entre estudantes do ensino fundamental e médio da rede pública de ensino nas 27 capitais brasileiras: 2004. São Paulo: CEBRID; 2005.

22 Brasil, Centro Brasileiro de Informação sobre Drogas Psicotrópicas (CEBRID), Universidade Federal de São Paulo (UNIFESP). II Levantamento domiciliar sobre o uso de drogas psicotrópicas no Brasil: estudo envolvendo as 108 maiores cidades do país. São Paulo: UNIFESP; 2006.

23 Pulcherio G, Bastos T, Strey M, Boni Rd. Consumo de álcool entre adolescentes do sexo feminino. Rev Psiq Clin. 2011;38:209-10.

24 Governo do Estado do Paraná, Secretaria de Estado da Educação, Superintendência da Educação, Diretoria de Políticas e Programas Educacionais, Coordenação de Desafios Educacionais Contemporâneos. Cultura e sociedade: prevenção ao uso indevido de drogas na escola [Internet]. 2010 Sep [cited 2018 May 21]. www.educadores. diaadia.pr.gov.br/arquivos/File/cadernos_tematicos/tematico_drogas 2010.pdf2010242 
25 Cook WK, Bond J, Greenfield TK. Are alcohol policies associated with alcohol consumption in low - and middle-income countries? Addiction. 2014;109:1081-90.

26 Brasil, Ministério da Educação. Curso emite certificados para educadores de todas as regiões [Internet]. 2010 Mar 09 [cited 2018 May 21]. http://portal.mec.gov.br/ultimas-noticias/222-537011943/15150-cursoemite-certificados-para-educadores-de-todas-as-regioes

27 Babor TF, Caetano R. The trouble with alcohol abuse: what are we trying to measure, diagnose, count and prevent? Addiction. 2008; 103:1057-9.

28 Bruckner TA, Scheffler RM, Shen G, Yoon J, Chisholm D, Morris J, et al. The mental health workforce gap in low- and middle-income countries: a needs-based approach. Bull World Health Organ. 2011; 89:184-94.

29 Miranda AE, Gadelha AM, Szwarcwald CL. [Behavior patterns related to sexual practices and drug use among female adolescents in Vitoria, Espirito Santo, Brazil, 2002]. Cad Saude Publica. 2005; 21:207-16.

30 Hoffman SD, Maynard RA. Kids having kids: economic costs and social consequences of teen pregnancy. Washington: Urban Insitute; 2008.

31 Brasil, Código Penal Brasileiro. Decreto lei $\mathrm{N}^{\circ} 2.848,7$ dezembro 1940. Artigos 124 a 128. www.planalto.gov.br/ccivil_03/decreto-lei/ Del2848compilado.htm

32 Bursztyn I, Tura LFR, Correa Jd S. Acesso ao aborto seguro: um fator para a promoção da equidade em saúde. Physis. 2009;19:475-87.

33 Brasil, Ministério da SaúdeSecretaria de Vigilância em Saúde, Departamento de Análise de Situação de Saúde. Guia de vigilância epidemiológica do óbito materno [Internet]. 2009 [cited 2018 May 21]. http://bvsms.saude.gov.br/bvs/publicacoes/guia_vigilancia_epidem_ obito_materno.pdf

34 World Health Organization (WHO). Health worker roles in providing safe abortion care and post-abortion contraception [Internet]. 2015 [cited 2018 May 21]. www.who.int/reproductivehealth/publications/ unsafe_abortion/abortion-task-shifting/en/

35 Martins-Melo FR, Lima MS, Alencar CH, Ramos AN Jr, Carvalho FHC, Machado MMT, et al. Tendência temporal e distribuição espacial do aborto inseguro no Brasil, 1996-2012. Rev Saude Publica. 2014; 48:508-20.

36 Sanchez ZM, Nappo SA, Cruz JI, Carlini EA, Carlini CM, Martins SS Sexual behavior among high school students in Brazil: alcohol consumption and legal and illegal drug use associated with unprotected sex. Clinics (Sao Paulo). 2013;68:489-94.

37 Strashny A. Characteristics of pregnant teen substance abuse treatment admissions. The CBHSQ Report. Rockville: Substance Abuse and Mental Health Services Administration; 2013.

38 Connery HS, Albright BB, Rodolico JM. Adolescent substance use and unplanned pregnancy: strategies for risk reduction. Obstet Gynecol Clin North Am. 2014;41:191-203.

39 Reardon DC, Coleman PK, Cougle JR. Substance use associated with unintended pregnancy outcomes in the national longitudinal survey of youth. Am J Drug Alcohol Abuse. 2004;30:369-83.

40 Sasaki RS, Leles CR, Malta DC, Sardinha LM, Freire Mdo C, et al. [Prevalence of sexual intercourse and associated factors among adolescents attending schools in Goiânia in the state of Goiás, Brazil]. Cienc Saude Colet. 2015;20:95-104. 